\title{
Evaluation of Residual Stresses in PVD Coatings by means of Tubular Substrate Length Variation
}

\author{
Harri Lille ${ }^{1, a,{ }^{*}}$, Alexander Ryabchikovi, ${ }^{1, b}$, Jakub Kõo ${ }^{1, c}, E^{2}$ Eron Adoberg ${ }^{2, d}$, \\ Valdek Mikli ${ }^{2, e}$, Jakob Kübarsepp ${ }^{2, f}$, Priidu Peetsalu ${ }^{2, g}$ \\ ${ }^{1}$ Institute of Forestry and Rural Engineering, Estonian University Life of Sciences, Kreutzwaldi \\ 5, 51014 Tartu, Estonia \\ ${ }^{2}$ Department of Mechanical and Industrial Engineering, Tallinn University of Technology, \\ Ehitajate tee 5, 19086 Tallinn, Estonia \\ aharri.lille@emu.ee, balexander.ryabchikov@emu.ee, cjakub.koo@emu.ee, \\ deron.adoberg@ttu.ee, 'valdek.mikli@ttu.ee, fjakob.kubarsepp@ttu.ee, ${ }^{9}$ priidu.peetsalu@ttu.ee
}

\section{Keywords: TiAIN Hard PVD Coating, Residual Stresses, Length Variation}

\begin{abstract}
The aim of the study was to determine macroscopic residual stresses in PVD coatings. The device for measurement of the length of the substrate was improved, where a change in tube length was reduced to the deflection of the middle cross-section of the elastic element whose deformation was measured by four strain gauges. The formulas for calculation of residual stresses are presented. For comparison a unilateral coating was deposited on a vertically fixed plate using the conventional curvature method. As an application, residual stresses in hard PVD TiAlN coatings were investigated. The microstructure and thickness of the studied coatings were investigated by means of scanning electron microscopy (SEM) in Zeiss EVO MA-15. The mean values of compressive residual stresses determined by both methods, for the studied coatings, were very high (3.1-6.5 GPa), irrespective of coating thickness, and practically equal with the measurement uncertainty of the method. The developed tube length variation method is reliable and applicable for determination of residual stresses in PVD coatings.
\end{abstract}

\section{Introduction}

Physical Vapour Deposition (PVD) coatings are used inter alia for blanking, punching and cutting applications and can be deposited both on plain and more complex surfaces [1, 2]. It is wellknown that residual stresses arising in coatings during the deposition process have an important effect on the service life of the coating through influencing its mechanical and tribological properties and adhesion.

The aim of the study was to determine macroscopic residual stresses in coatings vapoured on a vertically fixed cylindrical surface, using the deformation method, through measurement of the longitudinal length variation of the thin-walled tube, as well as to validate the results obtained with the conventional curvature method using the plate as the substrate. One batch of vertically fixed plates was prepared by depositing a unilateral coating on the front surface and the other batch of plates, by depositing it on the back surface. Thus a considerable amount of the vapoured target material was deposited on the fixing device as well [3]. On the other hand, using the tubular substrate, most of the coating was deposited on the outer surface of the tube (a small part of the coating was deposited on the nozzle) it is possible to estimate the values of residual stresses in coatings on cylindrical surfaces (e.g. cutting tools [4]).

The measuring device for determination of the longitudinal length change of the substrate was improved (Fig. 3), where tube length variation was reduced to the deflection of the middle crosssection of the elastic element whose deformation was measured by four strain gauges [5]. As an example of application, residual stresses were measured in hard PVD TiAlN coatings which are 
most widely used for cutting tools [4]. Also the microstructure and thickness of the studied coating were investigated by means of scanning electron microscopy.

\section{Evaluation of Residual Stresses in the Coating}

Plates (Fig. 1b) are only deposited from one side and should be placed gripped with a claw in the fixing device made of carbon steel [3]. Depending on the deflection of the plate, modified Stoney's formula will account for biaxial stresses [6]. In order to prevent deposition of the coating on the cross-section of the tube ends, they were closed by the nozzle (Fig. 1a); at the same time, the tube was vertically fixed, by the lower nozzle, to the rotary table of the chamber and was simultaneously rotated around its axis.

a)

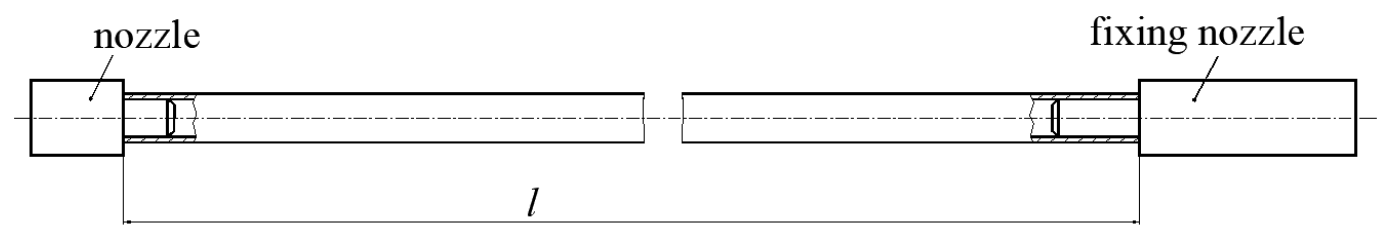

b) coated area claw

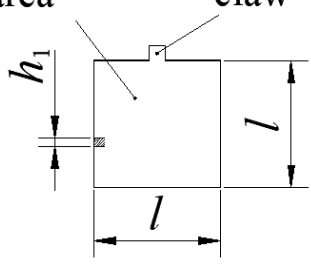

Fig. 1. Geometry of the substrate: tube with the nozzles before deposition (a); plate (b).

The mean values of residual stresses in the coatings were calculated from the length change of the tubular substrate [7]. As the coating was relatively thin it was assumed that residual stresses are distributed uniformly throughout coating thickness (Fig. 2).

a)

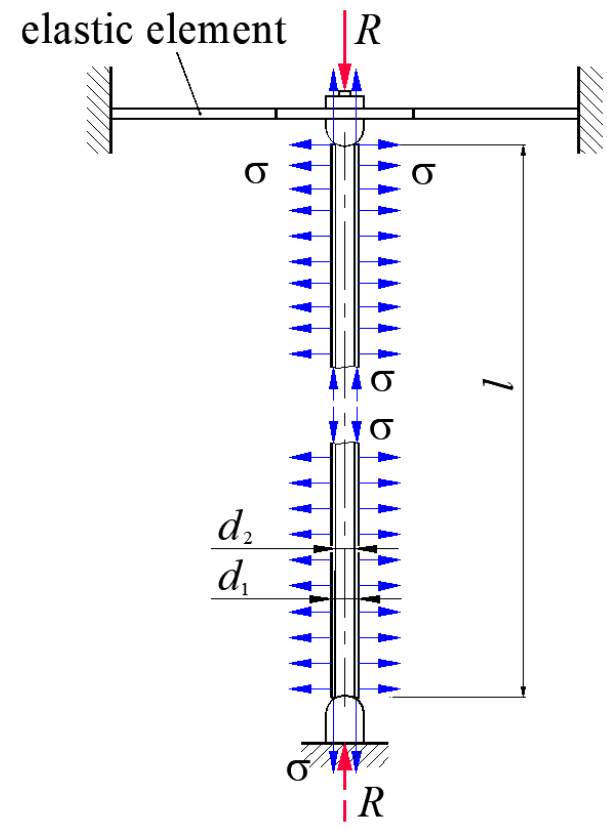

b)

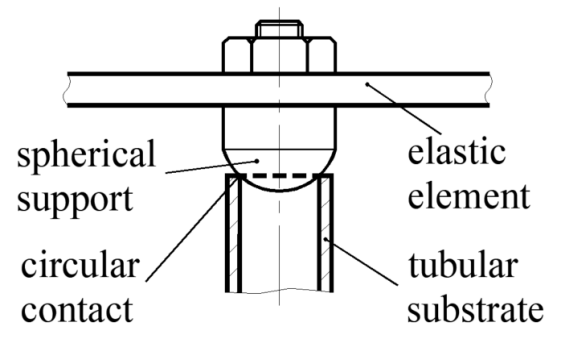

Fig. 2. A scheme for calculating residual stresses in the coating on the tubular substrate (effect on substrate after deposition), its fixation to the device (a) and circular contact of the tube (b). 
Hence the following expression can be used:

$$
\sigma=\frac{E_{1}}{2\left(1-\mu_{1}\right) r_{1}}\left(\frac{r_{1}^{2}-r_{2}^{2}}{l}+\frac{C}{E_{1} \pi}\right) \frac{\Delta l}{h_{2}},
$$

where $E_{1}$ and $\mu_{1}$ are the modulus of elasticity and Poisson's ratio of the substrate, $r_{1}$ is outer radius of the tube, $r_{2}$ is inner radius of the tube, $h_{2}$ is thickness of the coating, $l$ is length of the tube, $\Delta l$ is measured length variation of the tube, $C$ is rigidity of the elastic element. Considering our measuring device and the elastic element and the tube dimensions used, the share of member $C /\left(E_{1} \pi\right)$ is $1.7 \%$ of the second member in the brackets of Eq. 1; therefore it was not taking in to account and Eq. 1 is expressed as follows

$$
\sigma=\frac{E_{1}}{2\left(1-\mu_{1}\right) r_{1}}\left(\frac{r_{1}^{2}-r_{2}^{2}}{l}\right) \frac{\Delta l}{h_{2}} .
$$

During measurement of length variation, the lower end of the tube was fixed stationary and the upper end was pressed to the elastic element, which prestressed also the substrate (Fig. 3).

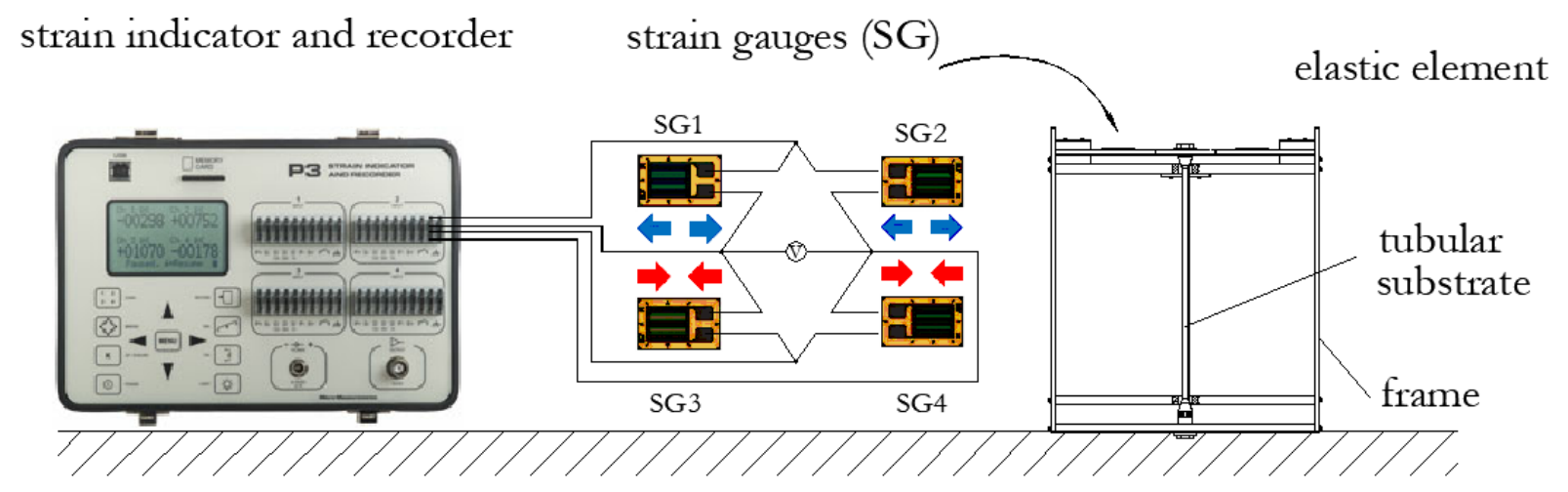

Fig. 3. A scheme of the measuring device for determination of the length of the tube and the substrate supported on the sphere.

To guarantee the centering of the tube in the measuring devise, the inner circular line of the cross section of its ends was in contact with the spherical surface of support (Fig. 2b). Consequently, the eccentric compressive load was minimized. The length of the tube was measured ten times before and ten times after deposition and mean values were used for calculating residual stresses in the coating.

Since calibration of the device is a separate task the scheme of which is presented in our paper [5], then now we can see in Fig 4a how the four strain gauges are glued in the longitudinal direction onto the free surface of the elastic element and joined to form a full bridge with four fully active arms (Fig. 4b). The elastic element was loaded manually step by step in the middle with weights of class M1, and deflection was measured with the potentiometric displacement tracer FWA050T to $50 \mathrm{~mm} / 0.001 \mathrm{~mm}$ and recorded with the Datalogger-AHLBORN ALMEMO® 2890-9-5. At the same time, the signals from the strain gauges were measured with the VPG P3 strain indicator and recorder. The results of calibration obtained in the case of unloading (its direction corresponds to tube length measurement direction) are presented graphically in Fig. 5.

The constants should be determined so that relations are approximated in the best way by minimizing the square of error (least squares regression). The deflection of the middle cross- 
section of elastic element $\Delta l$, depending on of the units of the strain indicator (Fig. 5a), was found by using the program MS Excel 2016 with the regression analysis function.

a)

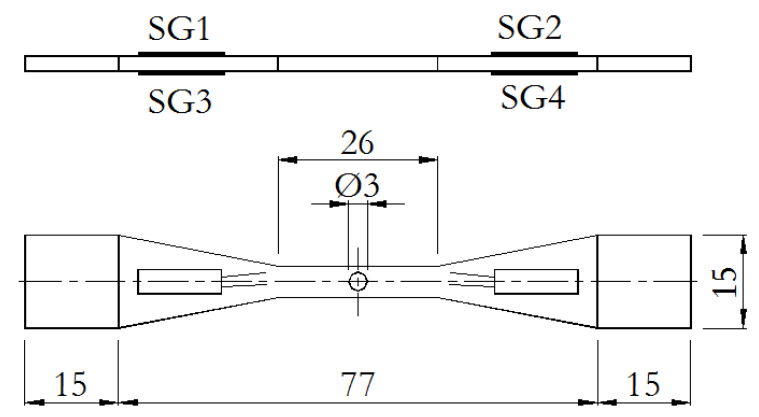

b)

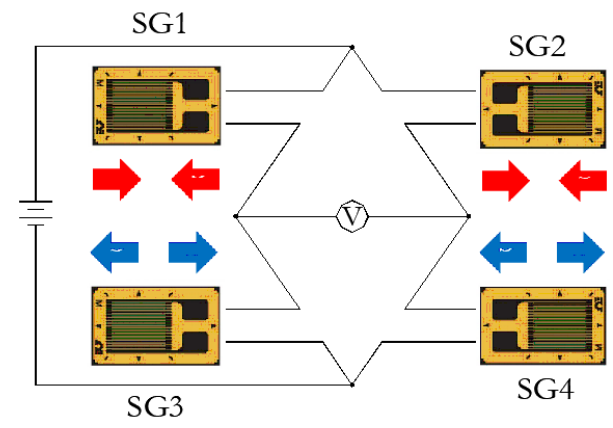

Fig. 4. The geometry of the elastic element and placement of the strain gauges (SG) (a); full bridge with four fully active arms (b).

a)

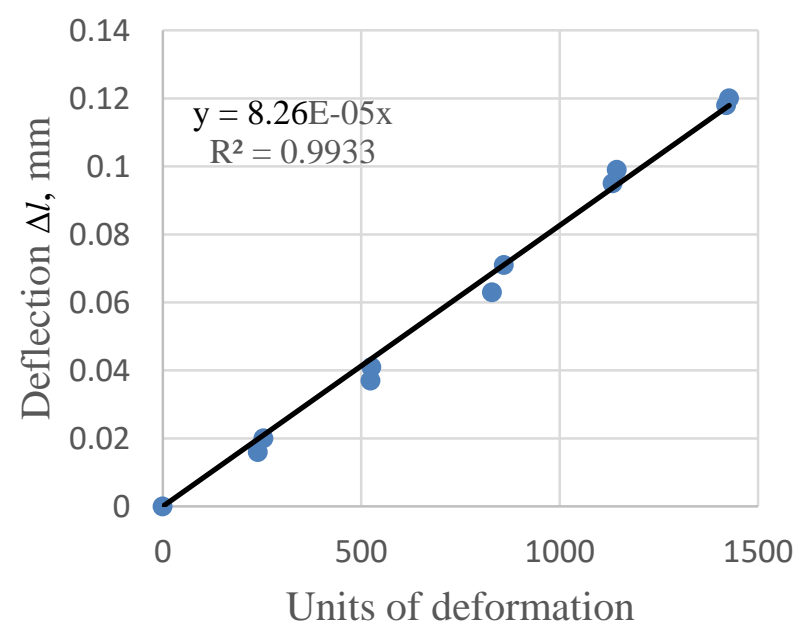

b)

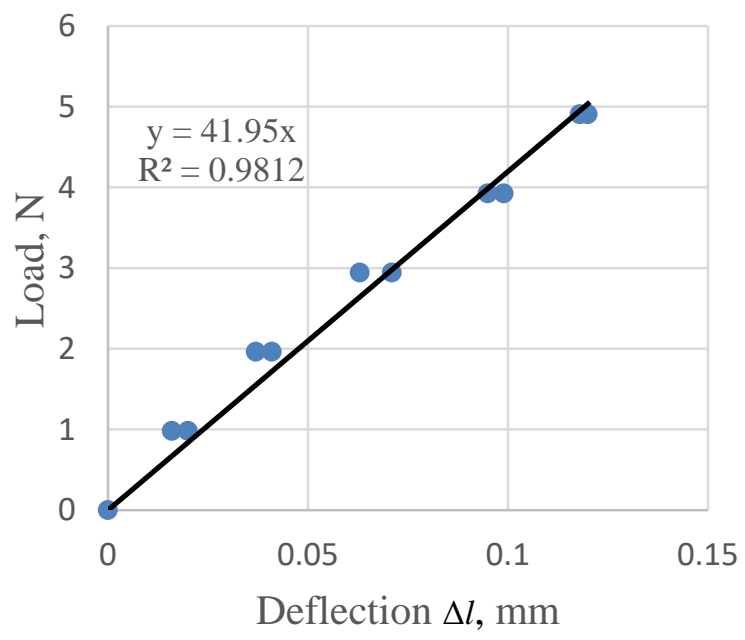

Fig. 5. Dependence of the units of the strain indicator on the deflection in the case of unloading (a); dependence of the load on the deflection of the elastic element (b).

As a result, the strain indicator constants are $8.26 \times 10^{-5} \mathrm{~mm}$ per unit of the strain indicator and recorder and the rigidity of the elastic element $C=41.95 \mathrm{~N} / \mathrm{mm}$.

\section{Example of application}

The studied PVD coatings were produced in the Laboratory of PVD Coatings at the Tallinn University of Technology. The PVD unit Platit $\pi$-80 with two rotating cathodes, embedded in the door of the vacuum chamber, was used for deposition. The tubes were fixed in the rotary table of the vacuum chamber vertically as were the plates in the fixing device (four specimens from each sample), but so, that one batch of the plates were prepared by deposition on the front surface (directed to the edge of rotary table) and the other batch, by deposition on the back surface (directed to the centre of the rotary table). After measuring the length variation of the coated tube and the deflection of the coated plate, three pieces were cut from one tube (two from the ends and one from the middle) with a length of $10 \mathrm{~mm}$ and two pieces were cut from the plates of 
different fixing specimens with dimensions of $10 \times 10 \mathrm{~mm}$, for scanning electron microscopy (SEM).

By means of SEM in Zeiss EVO MA-15, the microstructure of the coatings (Fig. 6) was investigated and their thicknesses were measured for calculating mean values. Physical and surface properties of the substrate material, dimensions and mean values of residual stresses in the coatings are presented on Table 1.

a)
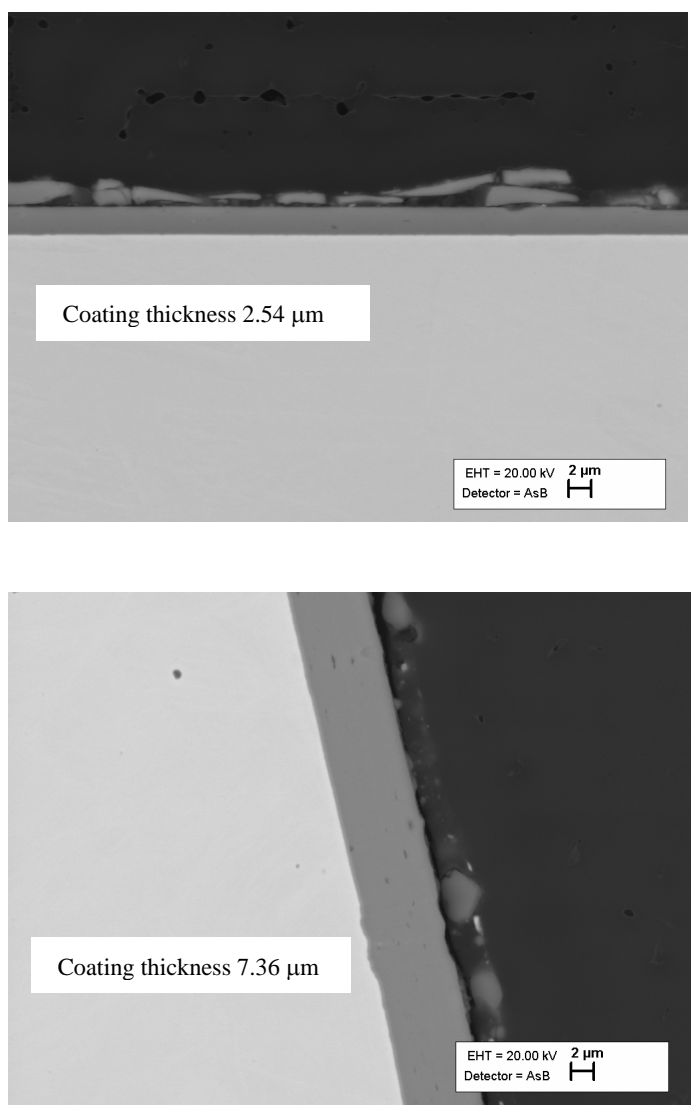

b)

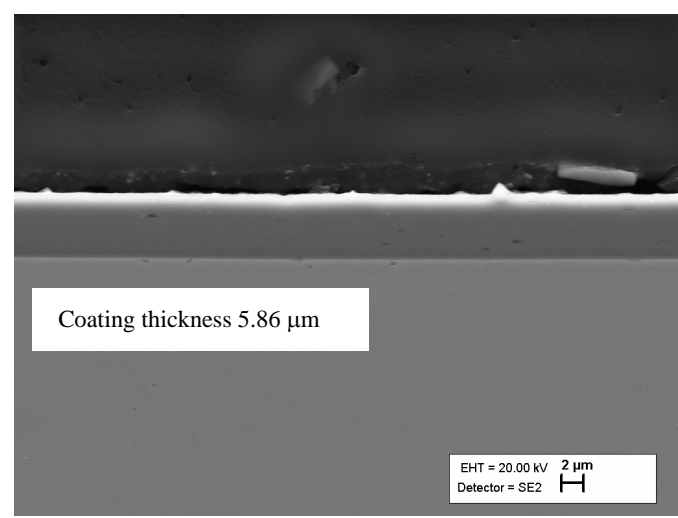

c)

Fig. 6. Coating on the back surface of the plate (a); coating on the front surface of the plate (b); coating on the tube (c).

Table 1. Physical and surface properties of the substrate material, dimensions and mean values of residual stresses in the coatings

\begin{tabular}{|l|c|l|l|l|l|l|l|}
\hline $\begin{array}{l}\text { Substrate } \\
\text { material }\end{array}$ & $\begin{array}{l}\text { Thickness, } \\
\text { diameters } \\
{[\mathrm{mm}]}\end{array}$ & $\begin{array}{l}\text { Usable } \\
\text { width, } \\
\text { length } \\
{[\mathrm{mm}]}\end{array}$ & $\begin{array}{l}\text { Modulus of } \\
\text { elasticity } \\
{[\mathrm{GPa}]}\end{array}$ & $\begin{array}{l}\text { Poisson's } \\
\text { ratio }\end{array}$ & $\begin{array}{l}\text { Surface } \\
\text { rough- } \\
\text { ness } \\
\text { Ra } \mu \mathrm{m}]\end{array}$ & $\begin{array}{l}\text { Thickness } \\
\text { of coating, } \\
{[\mu \mathrm{m}]}\end{array}$ & $\begin{array}{l}\text { Residual } \\
\text { stresses, } \\
{[\mathrm{GPa}]}\end{array}$ \\
\hline $\begin{array}{l}\text { Steel } \\
\text { plate }\end{array}$ & $\begin{array}{c}0.395^{*} \\
0.395\end{array}$ & $\begin{array}{l}19.75 \\
19.70\end{array}$ & 193.0 & 0.28 & $\begin{array}{c}0.024- \\
0.029\end{array}$ & $\begin{array}{l}5.86 \\
2.54\end{array}$ & $\begin{array}{l}-6.53 \\
-4.39\end{array}$ \\
\hline $\begin{array}{l}\text { Steel } \\
\text { tube }\end{array}$ & $\begin{array}{c}d_{1}=3.0 \\
d_{2}=2.5\end{array}$ & 167.5 & 193.0 & 0.25 & $\begin{array}{c}0.024- \\
0.029\end{array}$ & 7.36 & -3.10 \\
\hline
\end{tabular}

* The deposited surface is directed to the edge of the rotary table

We can see that the thickness of the coatings deposited on the tubular substrates and the thicknesses of the coatings deposited on the plates are significantly different. The coating deposited on the tube is thicker as some part of its coated surface is constantly forehead bombarded with target plasma atoms and ions. The coated surface of the plate is directed to the edge of rotary table and is bombarded with atoms and ions; the potential distance between the target and the substrate is minimal and the kinetic deposition parameters are larger. 
Consequently, the thickness of the coating is lager and also residual stresses arising in it are higher. The coated surface of the plate is directed to the centre of on rotary table and is bombarded with atoms and ions; the potential distance between the target and the substrate is maximal and the kinetic deposition parameters are smaller (the number of atoms in the ion beam is evidently lower). Also the thickness of the coatings is lower and residual stresses arising are lower. High compressive stresses arise in the coatings which help to reduce pre-existing structural defects.

\section{Summary}

The existing device was improved to enable to measure the length of the thin walled tubular substrate before and after deposition of the coating. The obtained length variation can be used as an experimental parameter for calculating the mean values of residual stresses in coatings.

Coatings are deposited on the substrate fixed vertically in a holder on the rotary table of the chamber and parallel to the cathode while one part of the plate is fixed onto the front surface and the other, on the back surface at the time of deposition.

The calculated mean values of residual stresses in hard PVD TiAlN coatings were: in the coating on the tube, $3.10 \mathrm{GPa}$; on the front surface of the plate, $6.53 \mathrm{GPa}$ and on the back surface on the plate, $4.39 \mathrm{GPa}$. The microstructure of the coating on the tube and on the plate, as well as the thickness of the coatings are presented.

\section{Acknowledgements}

This study was supported by the Estonian Ministry of Education and Research by Institutional Research Funding IUT 19-29 „Multi-scale structured ceramic-based composites for extreme applications“

\section{References}

[1] D.T. Quinto, Twenty-five years of PVD coatings at the cutting edge. Fall Bulletin. (2007) 17-22.

[2] T. Sampath Kumar, S. Balasivanandha Prabu, Geetha Manivasagam, and K. A. Padmanabhan, Comparison of TiAlN, AlCrN and AlCrN/TiAlN coatings for cutting-tool applications. Int. J. Min. Met. Mater. 21 (2014) 796-805.

[3] H. Lille, J. Kõo (et al). Comparation of Curvature and X-ray methods on Residual Stresses Measurements in Hard PVD Coatings. Materials Science Forum, 681 (2011) 455-460. Information on https://doi.org/10.4028/www.scientific.net/MSF.681.455

[4] Information on https://www.pvd-coatings.co.uk/applications/cutting-tools/

[5] H. Lille, A. Ryabchikov, J. Kõo (et al). Evaluation of Residual Stresses in PVD Coatings by means of Strip Substrate Length Variation and Curvature Method of Plate Substrate. Solid State Phenomena 267 (2017) 212-218. Information on https://doi.org/10.4028/www.scientific.net/SSP.267.212

[6] J. Kõo, J. Valgur, Residual stress measurement in coated plates using layer growing/removing methods: 100th anniversary of the publication of Stoney's paper "The tension of metallic films deposited by electrolysis”. Mater. Sci. Forum. 681 (2011) 165-170.

[7] J. Kõo, A. Ryabchikov. On the determination of residual stresses in coatings from measured longitudinal deformation of a wire substrate, in: Proc. 19th Symp. on Exp. Mech. of Solids J. Stupinicki (Ed.), Warsaw Univ. of Technology, Jachranka (Poland), 2000, pp. 319-324. Information on http://hdl.handle.net/10492/3803 